\title{
Fundamental aspects of the local approach to cutaneous ulcers ${ }^{*}$
}

\author{
Raquel Colenci ${ }^{1}$, Luciana Patricia Fernandes Abbade ${ }^{2}$
}

DOI: http:/ / dx.doi.org/10.1590/abd1806-4841.20187812

\begin{abstract}
Ulcers or wounds can be classified as acute or chronic. Their treatment involves overall assessment of the patient and choice of suitable local therapy, and the appropriate indication and use of products. Technological progress in the field of wound treatment has increased rapidly. Constant updating, with emphasis on available scientific evidence, is necessary to offer the best approaches to patients with acute and chronic wounds. A qualitative analysis of literature was conducted to identify scientific publications that update the concepts involved in local wound treatment, to present some resources that can aid the healing process and describe the different types of dressings available. This review includes wound assessment using the acronym TIME (tissue, infection/inflammation, moisture balance and edge of wound), cleaning and debridement, infection/ inflammation control, exudate control, dressing types and main indications.
\end{abstract}

Keywords: Occlusive dressings; Wounds and injuries; Wound healing

\section{INTRODUCTION}

Ulcers and wounds can be classified as acute or chronic. Acute wounds, mainly traumatic and postoperative in nature, usually maintain anatomical and functional integrity when properly healed. ${ }^{1}$

In contrast, chronic wounds progress slowly in the healing stages, presenting delayed, interrupted or paralyzed healing processes, according to intrinsic or extrinsic factors that have an impact on both the individual and their wound. ${ }^{1}$ Healing stops during the inflammatory or proliferative phases, with characteristics that hamper the healing process, such as accumulation of metalloproteinases, collagenases and elastase, which prematurely degrade collagen and growth factors. They also present a hypoxic microenvironment (low oxygen tension), leading to fibroblast proliferation and, consequently, to increased tissue fibrosis. In addition, biofilm formation and the propensity to be colonized by bacteria and fungi are factors that delay the healing process. Lower limb ulcers (venous, arterial and neuropathic) and pressure injury are considered chronic.

The treatment of acute and chronic wounds involves a global evaluation of the patient and the choice of appropriate therapy, targeting not only the wound, but also its cause. The choice of therapy must be made in accordance with the available evidence for the indication and use of the therapeutic products in an appropriate

\footnotetext{
Received 03 November 2017.

Accepted 31 March 2018.

* Work conducted at the Department of Dermatology and Radiotherapy, Faculdade de Medicina de Botucatu, Universidade Estadual Paulista, Botucatu (SP), Brazil.

Financial support: None.

Conflict of interest: None.

1 Technical Section of Nursing in Dermatology, Hospital das Clínicas, Faculdade de Medicina de Botucatu, Universidade Estadual Paulista, Botucatu (SP), Brazil.

2 Department of Dermatology, Faculdade de Medicina de Botucatu, Universidade Estadual Paulista, Botucatu (SP), Brazil.
}

\section{MAILING ADDRESS:}

Raquel Colenci

E-mail: raquelcolenci@gmail.com 
manner. Thus, we conducted a qualitative analysis of the literature to identify scientific publications, seeking to update concepts the involved in wound resolution and its various aspects, emphasizing the importance of multidisciplinary action as well as the holistic perception of the patient. It should be noted that technological progress in the field of wound treatment has been rapid; thus, we present resources that can enhance the healing process and describe the main types of products available in the Brazilian market.

\section{WOUND EVALUATION}

In the practice of wound care, the acronym TIME was developed in 2003 by a group that works with wound healing. The purpose of using this acronym was to facilitate the evaluation of factors that negatively interfere in the healing process, as well as to optimize wound management. It has been widely used as a practical guide for the evaluation and management of chronic wounds in particular. There is no systematic way of evaluating acute wounds; however, TIME can be applied in some situations. Thus, TIME describes basic concepts related to clinical observation and interventions associated with bed preparation, grouped into four areas: $:^{2,3}$

Tissue: evaluation and debridement of non-viable tissue on the surface of the wound.

Infection/inflammation: assessment of the etiology of each wound; use of topical antiseptic and/or systemic antibiotic to control infection; and management of inappropriate inflammation unrelated to infection.

Moisture imbalance: assessment of the etiology and management of wound exudate.

Edge: assessment of non-advancing or undermined wound edges (and state of the surrounding skin).

Based on this concept, we will describe the steps of local wound treatment process.

\section{WOUND CLEANING}

Bed preparation, including cleaning and debridement, is an important principle of management, since the wound needs to be clean and have good granulation tissue to heal. ${ }^{4}$

There is no strong evidence in the literature regarding cleaning and debridement; however, there is a strong consensus that healing is impeded by the presence of dead tissue, foreign bodies and debris. So, the initial recommendation for treatment is that dead tissues should be radically removed. ${ }^{5}$

Cleansing is a key step in local treatment and should be performed by applying nontoxic fluid capable of removing liquefied necrotic tissue, exudate and foreign bodies, including the remains of previous cover, from the wound bed without causing damage to viable tissues. This will create an optimal environment for healing. ${ }^{6}$

There is no scientific evidence for which cleaning technique is best, regardless of the environment in which the dressing is performed (hospital, outpatient or home). A point of divergence is the understanding and use of the terms 'sterile' and 'clean' as applied in clinical practice.

First, antisepsis can be conceptualized as the destruction of existing microorganisms in superficial or deep layers of the skin, by the application of a hypoallergenic, low-causticity germicidal agent that can be applied to living tissue. ${ }^{7}$ The initial concept of antisepsis dates back to the end of the 18th century. There were several subsequent attempts to create a product that could achieve antisepsis and be used safely. The main problems associated with many antiseptics were not related to the efficacy of antisepsis, but to the effects that occurred due to systemic absorption and tissue toxicity. ${ }^{8}$

\section{Wound cleaning technique}

There are two main points of discussion in clinical practice regarding wound cleaning. The first one relates to which cleaning technique is the most appropriate: clean or sterile. The other point relates to the choice of the most suitable cleaning solution.

The concept of sterile dressing refers to the microorganism-free environment. It involves strategies used in patient care to reduce exposure to microorganisms and keep objects and areas free of microorganisms as much as possible. This involves careful hand washing and the use of sterile fields, gloves, instruments and dressings. The sterile technique is considered most appropriate in acute care hospital sectors for patients at risk of infection and for performing certain procedures such as mechanical and surgical debridement. ${ }^{9,10}$

The clean technique means 'dirt-free' and involves patient-care strategies to reduce the overall number of microorganisms, or to prevent or reduce the risk of transmission of microorganisms from one person to another or from one place to another. It involves hand washing, maintaining a clean environment, using sterile instruments and procedure gloves, and preventing direct contamination of materials. These practices are most appropriate for chronic care, home care, patients with low risk of infection and patients with chronic wounds. ${ }^{9,10}$

There is neither consensus among experts nor scientific evidence on the use of clean or sterile dressing techniques in the cleaning of chronic wounds. The research is limited and inconclusive on this issue, particularly regarding the impact on the healing process. Limited evidence indicates that the clean technique reduces costs and should reduce the performance time and is therefore recommended for patients with chronic wounds in the home environment. $^{9}$

\section{Cleaning solutions for wounds}

Regarding cleaning solutions, saline (physiological saline $0.9 \%$ ) is most suitable for most wounds, for being isotonic, having the same plasma $\mathrm{pH}$, being non-allergenic and not interfering in the normal healing process. ${ }^{11}$ However, when the wound presents a large quantity of devitalized tissue, is critically colonized or infected, and has malodor, cleansing with saline $0.9 \%$ can be insufficient to achieve cleanness. Therefore, in clinical practice, especially when faced with the situations mentioned above, other substances with greater antiseptic power are sought.

Chlorhexidine, acetic acid, potassium permanganate, and Dakin solution are some of the commonly used antiseptics. Such compounds have antibacterial action and are generally safe when applied on intact skin. However, such agents may cause some toxicity in the granulation tissue, such as prolonging the acute inflammatory response or delaying the production of collagen, and 
are therefore not recommended for cleaning chronic wounds. ${ }^{12}$

A systematic review compared the use of tap water and normal saline (saline $0.9 \%$ ) for wound cleaning. ${ }^{11}$ The study showed that although various solutions have been recommended for cleansing wounds, normal saline is favored. Tap water is commonly used in the community for cleansing wounds because it is easily accessible, efficient and cost effective; however, there is an unresolved debate about its use. There is no evidence that using tap water to cleanse acute wounds in adults or children increases or reduces infection. There is no strong evidence that cleansing wounds per se increases healing or reduces infection. There is a caveat regarding the use of tap water in countries that lack an adequate supply of drinking water.

Iodine is one of the best-known antiseptics and has been used for over a century. However, its use in the treatment or prevention of wound infection is debated, because iodine can cause allergic reactions, is less effective due to low penetration, and negatively influences tissue regeneration due to its toxic effect on cells. ${ }^{13}$ The results of research on its use in topical therapy of chronic wounds did not allow for the definition of its usage trend. New, more effective iodophor preparations with fewer adverse effects are currently being sought, probably as an alternative for future research. ${ }^{14}$

In contrast, a systematic review of randomized clinical trials that investigated the possible positive and negative clinical effects of iodine in the treatment of all kinds of wound showed that iodine did not reduce or prolong wound healing time, compared to other dressing or antiseptics agents. ${ }^{13}$ The review concluded that the use of iodine in wound treatment is still defensible, because the best available evidence maintains that there are no suspected harmful effects nor a delay in wound healing, particularly in chronic wounds and burns. In addition, the effects of iodine are the most well documented among currently available antiseptic agents. The review also concluded that high-quality clinical trials are needed to address the efficacy of iodine for treatment and prevention of wound infection.

Polyhexanide is another substance currently used for wound cleaning. Since the 1960s, it has been used in the industry with good bactericidal efficacy, though its toxicity remained unknown. After medical research, Switzerland approved its use in 1994. It is currently an antimicrobial substance highly suitable for use in critically colonized or infected acute and chronic wounds. This positive evaluation is attributable particularly to its broad antimicrobial spectrum, good tolerability by cells and tissues, ability to bind the organic matrix, low risk of contact sensitization, and healing-promoting effect. In addition, there is no reported risk of developing resistance to microorganisms. ${ }^{8}$ Polyhexanide is a broad-spectrum antiseptic with excellent tolerance and a low-risk profile. Physical-chemical action prevents the development of bacterial resistance. Thus, polyhexanide is suitable and useful to fight multi-resistant bacteria. ${ }^{8,15}$ Polyhexanide associated with betaine surfactant has been identified as effective in autolytic debridement, and a study found that the solution promoted the preparation of the wound bed, reduced inflammatory signs and accelerated healing in venous ulcers. ${ }^{4}$

Thus, according to these data, it is possible to conclude that chronic wounds can be cleansed with taper water or saline solution.
Polyhexanide is an important ally in this process; however, it is still considered expensive.

\section{WOUND DEBRIDEMENT (LETTER T OF TIME)}

The management of the wound bed of ulcerated tissue includes measures to remove devitalized structures, such as necrotic tissue or foreign bodies, and excess bacterial load. It can be summarized by the term debridement and falls under the letter $\mathrm{T}$ of TIME. ${ }^{2,16}$ The rationale for removing such wound components is that devitalized and infected tissues favor the persistence of wound inflammation through the release of pro-inflammatory cytokines and chemokine.

There are five debridement types: autolytic, mechanic, surgical, enzymatic and biological. ${ }^{17}$ The type of debridement should be chosen based on the amount of devitalized tissue to be removed, the associated infectious condition and individual patient factors (sensitivity to pain and risk factors). ${ }^{16,17}$ It is also worth mentioning that debridement can be episodic or continuous and often involves a combination of techniques in the same patient.

\section{Autolytic debridement}

Characterized by parallel enzymatic cleaning processes that spare granulation tissue, autolytic debridement is thus selective and highly efficient within the context of physiological healing. It is achieved by using an occlusive dressing that keeps the wound bed moist, activating the patient's own phagocytic cells and proteolytic enzymes, and favoring the degradation of non-viable tissues. It is not indicated for wounds with areas of extensive necrosis, because it is less efficient. ${ }^{17,18}$

Hydrogels and hydrocolloids are the most suitable products for this type of debridement, but their indication still needs to be critically assessed because of the increased potential for irritation and sensitization, particularly in patients with leg ulcers. ${ }^{17}$

Polyhexanide combined with betaine in gel form is another product indicated for this type of debridement. ${ }^{19}$

\section{Mechanical debridement}

It is an effective and inexpensive method of debridement by which chronic wounds can become acute and consequently undergo the physiological phases of healing. It is contraindicated when pathergy phenomena are likely, as in pyoderma gangrenosum. The disadvantage of this method is that it is not selective and can be painful. ${ }^{17}$

It can be realized through hydrotherapy, with the use of water jets to wash residue from the surface of the wound. Another form of mechanical debridement is wet-dry therapy, where wet gauze is applied to a wound and allowed to dry. Once dry, the gauze is removed from the wound bed, carrying with it any adherent viable and non-viable tissue. ${ }^{16}$

Negative pressure therapy may facilitate debridement of non-viable tissues, but when more than $20 \%$ of devitalized tissues are present, removal of these tissues is indicated prior to the use of negative pressure. ${ }^{3}$ 


\section{Surgical debridement}

Performed with a scalpel, curette or scissors, and requiring training, surgical debridement is indicated for signs of local infection, systemic infection focused on the wound, and large areas of necrosis or devitalized tissue. Superficial surgical debridement performed with a curette and local anesthesia is indicated for chronic wounds with less devitalized tissue and for wounds with critical colonization, to possibly rupture biofilms. Pain should be treated appropriately when necessary. ${ }^{5}$

The method is fast but also painful, and consideration should be given to bleeding risk, bacterial translocation with bacteremia, damage to vital structures such as tendons and nerves, and the potential risk of anesthesia. ${ }^{16}$

\section{Enzymatic debridement}

This type of debridement involves the application of proteolytic enzymes on the wound bed, which chemically digest non-viable tissues. The effective action requires several weeks of treatment. It is a $\mathrm{pH}$-dependent process, i.e., the action of proteolytic enzymes is influenced by the $\mathrm{pH}$ of the wound bed and can be deactivated by other agents. Examples of proteolytic enzymes are papain, collagenase and fibrinolysin. ${ }^{17,20}$ Item 8 of this article gives a description of each of these products.

\section{Biological debridement}

Also known as maggot therapy, this method involves the application of laboratory-raised larvae on the wound bed. The larval secretions (leucine, aminopeptidases, collagenases, and others) cause the necrotic tissue to rupture, saving vital tissues, and has an anti-inflammatory and pro-angiogenic effect. However, this method is not systematically available in Brazil. ${ }^{17}$

\section{INFECTION/INFLAMMATION WOUND CONTROL (LETTER I OF TIME)}

The prevention and management of critical colonization and biofilm in chronic wounds is the primary goal of the treatment, the presence of biofilm being recognized as one of the main causes of delayed healing in chronic wounds. ${ }^{4}$

Biofilm is characterized by the formation of three-dimensional mosaics of microorganisms that accumulate and organize on surfaces within an extracellular polymer, or glycocalyx, with intercalated water channels. They are resistant to conventional therapies, the mechanisms of which are under study.,21

Infected chronic wounds necessitate strategies for systemic treatment with antibiotics, whereas for uninfected wounds where the presence of biofilm prevents healing, the appropriate strategies are local and aim to break the biofilm, facilitating reduction of bacterial load and disfavoring its reconstitution. ${ }^{9}$

After proper cleaning of the wound bed and removal of the unviable tissues through debridement, an antimicrobial product should be used to prevent biofilm from reforming. Many antibacterial products are cited in the literature and may be used, including acetic acid, honey, iodine, polyhexanide and silver. ${ }^{4}$ The choice must take into account the toxicity of the product to granulation tissue.

Regarding the use of topical or systemic antibiotics, a systematic review of the effects of systemic antibiotics, topical antibiotics and antiseptics on the healing of venous ulcers found no evidence to support the routine use of systemic antibiotics to promote their healing. However, the lack of reliable evidence means that the discontinuation of those agents cannot be recommended. The review also concluded that, in light of the growing problem of bacterial resistance to antibiotics, current prescription guidelines should recommend that antibacterial preparations be used only in cases of clinical infection, not for bacterial colonization. ${ }^{22}$

It is important to note that any open wound is colonized by microorganisms; however, there are no clinical consequences when there is no evidence of infection and healing occurs as expected. Systemic antibiotics are recommended when wounds show clinical signs of infection, such as purulent secretion or some of the cardinal signs of inflammation (erythema, heat, pain or tenderness, or hardening). The use of topical antimicrobial agents such as silver or iodine dressing is indicated and aids in the removal of biofilm. Topical treatments may be found useful in the growing problem of multi-resistant organisms that are intractable with most systemic agents. ${ }^{12}$

Wounds are colonized to varying degrees, but when the body>s defenses are weakened locally or systemically, or the colonizing agent is persistent, the level of colonization becomes critical and may lead to an established clinical infection. Several types of products and dressings to control colonization and infection have been studied.

The focus of wound care is the challenge of preventing infection and promoting healing. Dressings that incorporate silver to control local infection and speed healing are widely used. However, the studies that have evaluated its use note some contradictions. In a systematic review, the metanalysis results reinforce the proposition that silver-impregnated dressings improve the healing of lower limb wounds in the short term. However, due to the lack of trial data with longer a follow-up period, the long-term effects remain obscure. $^{23}$

Another study concluded that clinical trials have been poor and small, showing no sufficient evidence to support the use of dressing and topical agents containing silver. In general, these treatments have not been shown to promote healing or infection prevention, indicating the need for new studies. ${ }^{24}$ The same conclusion was found by the Cochrane systematic review, where the authors concluded that evidence is lacking to support the routine use of dressings with silver. ${ }^{22}$

\section{EXUDATE CONTROL (LETTER M OF TIME)}

Exudative wounds are hard to control, and choosing an adequate dressing is difficult. Many factors such as wound size, presence of infection and volume of exudate must be considered. If not handled effectively, the quantity of exudate can be a problem, leading to maceration and peri-ulcer dermatitis, delayed healing, malodor, infection and increased number of dressing changes, increasing financial expenses. Other important factors in minimizing exudate include limb elevation to reduce edema and use of diuretics to treat heart failure. ${ }^{25}$

The main dressings for exudative wounds are calcium al- 
ginate sheets, hydrofiber, activated charcoal and foams. Negative pressure therapy is also an option for this type of wound.

\section{MANAGEMENT OF PERI-ULCER SKIN (LETTER E OF} TIME)

Evaluation of peri-ulcer skin and the edges of the wound may indicate the progression of wound contraction and epithelialization, as well as whether the proposed treatment is effective or needs reevaluation. Evaluating the condition of the peri-ulcer skin is important, since moisture and maceration of edges can impede healing and therefore, when present, indicate the need for dressings that are better able to absorb excess exudation, such as those already mentioned in regard to exudate control. ${ }^{2,3}$

\section{MAIN TYPES AND INDICATIONS OF PRODUCTS AND DRESSINGS USED IN WOUND TREATMENT}

Choosing the correct dressing is a difficult and challenging task. In this sense, some factors should be considered: ${ }^{26}$

Factors related to wound and adjacent skin: etiology, size, depth, anatomic localization, exudate volume, risk or presence of colonization/infection; adjacent skin conditions, such as the presence of peri-ulcer maceration and contact eczema

Patient-related factors: nutritional conditions, underlying diseases, need for pain control, preferences

Factors related to dressing: indication, contraindication, advantages and disadvantages, availability, durability, adaptability, ease of use and access to product

The most suitable dressing type will depend on the wound healing phase. The process is dynamic, and one patient can use various dressing types during the evolution of the wound, depending on its condition at each evaluation. Thus, we will describe the main types of dressings available in Brazil for clinical use, their indications, advantages and limitations. It is important to note that the purpose of this review is not to cite all types and combinations of dressings; the technological development in this area is considerable, and some dressings recently launched or yet to be released in Brazil may therefore not be addressed below. The authors declare no conflicts of interest in this study. The citation of the top trading names is intended to exemplify the main brands available in the Brazilian market. It is also worth noting that most occlusive and semi-occlusive dressings are found only in specific stores that sell surgical and hospital supplies, and some are available in the primary care network.

\section{Essential fatty acids}

Composition: fatty acids of vegetable origin

Action: described as having the ability to form a protective barrier on the skin, preventing maceration, as well as an important role in the processes of cellular inflammation, local cellular nutrition and the regenerative capacity of tissue, providing relief after its application ${ }^{27}$

Indication: treatment and prevention of dermatitis and lesions

Dressing change: gauze or rayon soaked in oil; changed every 24 hours
Advantages: low cost, easy application and access

Limitations: may cause contact dermatitis by sensitization in some cases. Lack of scientific evidence based on clinical studies on the action of essential fatty acids in wound healing ${ }^{27}$

Cost: $200 \mathrm{ml}$ bottle R $\$ 8$ - R $\$ 30$

Trading names: Dersani ${ }^{\circledast}$, AGE Curatec ${ }^{\circledast}$, Óleo de Girassol Moph Derm ${ }^{\circledast}$

\section{Collagenase}

Composition: selective enzyme (collagenase) derived from the bacterium Clostridium histolyticum

Action: considered an effective and selective method for acting on the collagen present in necrotic tissue without damaging the granulation tissue ${ }^{28}$

Indication: primary dressing for debridement maintenance Dressing change: every 24 hours

Advantages: selective enzyme debridement ${ }^{20,29}$

Limitations: hypersensitization and mild pain in some cases, and a slow debridement process

Cost: $30 \mathrm{~g}$ tube $\mathrm{R} \$ 40$

Trading names: Kollagenase ${ }^{\circledR}$, Iruxol mono ${ }^{\circledR}$

Fibrinolysin

Composition: fibrinolysin, deoxyribonuclease and chloramphenicol

Action: a combination of proteolytic enzymes of bovine origin that act on the extracellular tissue, disintegrating cells of necrotic tissues, not acting on living tissues ${ }^{30}$

Indication: primary dressing for debridement maintenance Dressing change: every 24 hours

Advantages: enzyme debridement

Limitations: hypersensitization and mild pain in some cases, and slow debridement process. There are no recent studies on this product.

Cost: $10 \mathrm{~g}$ tube $\mathrm{R} \$ 30$

Trading names: Fibrinase ${ }^{\circledR}$

\section{Papain}

Composition: derived from the latex of papaya Carica papa$y a$ (leaf and fruit of green papaya); the fruit extract is more effective than the leaf extract. Papain is a complex mixture of proteolytic enzymes and peroxidases

Action: its active agents promote enzymatic debridement, as they cause proteolysis, protein degradation in tissue amino acids, devitalization and necrosis. Papain is used in different pharmaceutical formulations, such as powder, gel, cream and solution, in concentrations from $2 \%$ to $10 \%$. Currently, the recommended concentrations are $2 \%$ for stimulating the formation of granulation tissue; 4-6\% for removing liquefactive necrosis; and 8-10\% for removing coagulative necrosis. Other characteristics of this substance are its anti-inflammatory, bacteriostatic and bactericidal capacities. The antibacterial action was demonstrated only at the $10 \%$ concentration $^{31}$

Indication: primary dressing for debridement maintenance Dressing change: every 24 hours

Advantages: debridement and antibacterial action

Limitations: Patients who have allergic reaction to Carica 
papaya latex may have a similar reaction to papain. Some patients present low to moderate pain intensity depending on the percentage of papain used. The dressing is not marketed in Brazil and is available only through pharmaceutical compounding

Cost: variable, because it is produced by compounding pharmacies

\section{Silver sulfadiazine}

Composition: $1 \%$ hydrophilic silver sulfadiazine

Action: silver promotes protein precipitation and acts directly in the cytoplasmic membrane of bacterial cells, causing immediate bactericidal and residual bacteriostatic action by releasing small amounts of ionic silver

Indication: wounds with critical colonization or infection, needing bacterial load control ${ }^{32}$

Dressing change: every 24 hours

Advantages: possible antibacterial action

Limitations: hypersensitivity to sulfas. Lack of scientific evidence that silver promotes a decrease in the bacterial load of chronic wounds and accelerates their healing

Cost: $50 \mathrm{~g}$ bottle $\mathrm{R} \$ 25$

Trading names: Dermazine ${ }^{\circledast}$, Dermacerium ${ }^{\circledast}$ (with nitrate cerium)

Cadexomer iodine

Composition: Cadexomer iodine

Action: Antibacterial and cleaning effect, with absorption of exudate from the wound and promote debridement. Available as ointment, powder, paste (concentration of $0.9 \%)^{22}$

Indication: wounds with critical colonization or infection needing bacterial load control

\section{Dressing change: up to 72 hours}

Advantages: there is evidence for the topical treatment of infected chronic wounds ${ }^{12,22,33}$

Limitations: not effective on dry and clean wounds; not for patients with iodine sensitivity, nor for children, pregnant or lactating women; not indicated for patients with thyroid disorders or renal dysfunction (Hashimoto's thyroiditis or goiter nodules).

Cost: $10 \mathrm{~g}$ tube $\mathrm{R} \$ 65$

Trading names: Iodosorb ${ }^{\circledast}$

\section{Non-adherent gauze}

Composition: combination of cellulose acetate mesh impregnated with emulsion based on petrolatum, paraffin or essential fatty acids

Action: protects regenerated tissue, minimizing trauma during dressing exchange. Non-adherent gauze allows the exudate to pass freely to secondary covering, preventing excessive exudation and maceration of the wound, and reduces the risk of adherence to the wound bed

Indication: wound with mild to moderate exudate; widely used in graft donor areas

Dressing change: up to 7 days

Advantages: non-adhesion facilitates removal of the dressing, resulting in little or no pain to the patient and does not damage the granulation tissue. A study recommends the use of petrolatum instead of topical antibiotics as a prophylactic measure to prevent post-surgical wound infections in the outpatient dermatological environment ${ }^{34}$

Limitations: Not indicated for wounds that are infected and have a large amount of exudate

Cost: measuring $7.6 \times 7.6 \mathrm{~cm} \mathrm{R} \$ 17 /$ unit

Trading names: Adaptic ${ }^{\circledR}$, Curatec Compressa com Emulsão de Petrolatum ${ }^{\circledast}$, Curatec AGE 30 Rayon $^{\circledast}$

\section{Polyurethane film}

Composition: Thin $(0.2 \mathrm{~mm})$ surface of polyurethane and other synthetic polymers, with adhesive on one side

Action: Semi-occlusive membrane, which allows the exchange of oxygen and water vapor between the wound and external environment, remaining impermeable to liquids and bacterial contamination

Indication: primary or secondary dressing for minimally exudative wounds. Used primarily for catheter dressings, prevention of pressure injury or treatment of stage I pressure injury, first degree burns, graft donor area

Dressing change: average of 3 to 7 days, according to saturation

Advantages: transparency that allows the visualization of the wound or the primary dressing

Limitations: may cause exudate accumulation and maceration if used inappropriately for exudative wound ${ }^{35}$

Cost: measuring $10 \times 10 \mathrm{~cm} \mathrm{R} \$ 28 /$ unit

Trading names: Curatec $^{\circledR}$ sterile transparent film,Askina ${ }^{\circledast}$ Derm, Bioclusive $^{\circledast}$, Opsite ${ }^{\circledR}$

\section{Hydrocolloids}

Composition: film-bound polyurethane foam and gel-forming agents such as carboxymethylcellulose, pectin and gelatin (Figure 1)

Action: keeps wound moist and promotes autolysis, causing a reduction in local $\mathrm{pH}$ that allows the defense mechanism to work more efficiently, favoring autolytic debridement

Indication: wounds that have good granulation tissue or a low amount of devitalized tissues and have a low or moderate amount of exudate

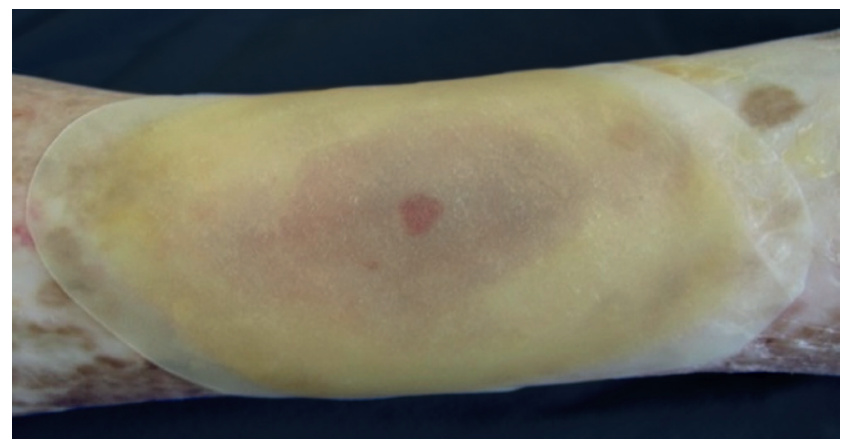

Figure 1: Hydrocolloid dressing

Source: Dermatology Department of Botucatu Medical School 
Dressing change: every seven days, depending on the amount of exudate

Advantages: waterproof and bacterial, thermal insulation

Limitations: opaque dressing that does not allow visualization of wound bed without the removal of the dressing. It may cause maceration of the peri-ulcer $\mathrm{skin}^{25}$

Cost: measuring $10 \times 10 \mathrm{~cm} \mathrm{R} \$ 30 /$ unit

Trading names: Curatec ${ }^{\circledR}$ Hydrocolloid, Askina ${ }^{\circledR}$, Hydro ${ }^{\circledR}$, Duoderm $^{\circledast}$, Curactive $^{\circledast}$, Coomfeel $^{\circledR}$, Nuderm ${ }^{\circledast}$

\section{Foams or hydropolymers}

Composition: synthetic polymers, with polyurethane and silicone (Figure 2) ${ }^{25}$

Action: provides thermal insulation and protects against shear, while wound contact layer allows for non-traumatic dressing changes $^{35}$

Indication: There are several types of polyurethane foam dressings that are coupled with a silicone border and with silver. Indications are for mild to moderately exudative wounds. ${ }^{35}$ foam dressing coupled with a silicone border may be indicated for prevention of pressure injury ${ }^{36}$

Dressing change: change the dressing whenever fluid is present on the borders of the foam pad, or every 7 days at most

Advantages: diversity of sizes and shapes, exudate control for various types of wound. Some patients experienced less pain when compared to traditional gauze dressing 25

Limitations: may promote the development of excess fetid drainage, requiring frequent dressing changes. Polyurethane can provoke allergic reaction, does not have the ability to bind or modulate the proteases, and may delay healing

Cost: measuring $10 \times 10 \mathrm{~cm} \mathrm{R} \$ 45 /$ unit

Trading names: Curatec ${ }^{\circledast}$ polyurethane foam, Allevyn ${ }^{\circledR}, \mathrm{Bi}-$ atain no adhesive ${ }^{\circledR}$, Biatain silicone ${ }^{\circledast}$, Mepilex $^{\circledR}$

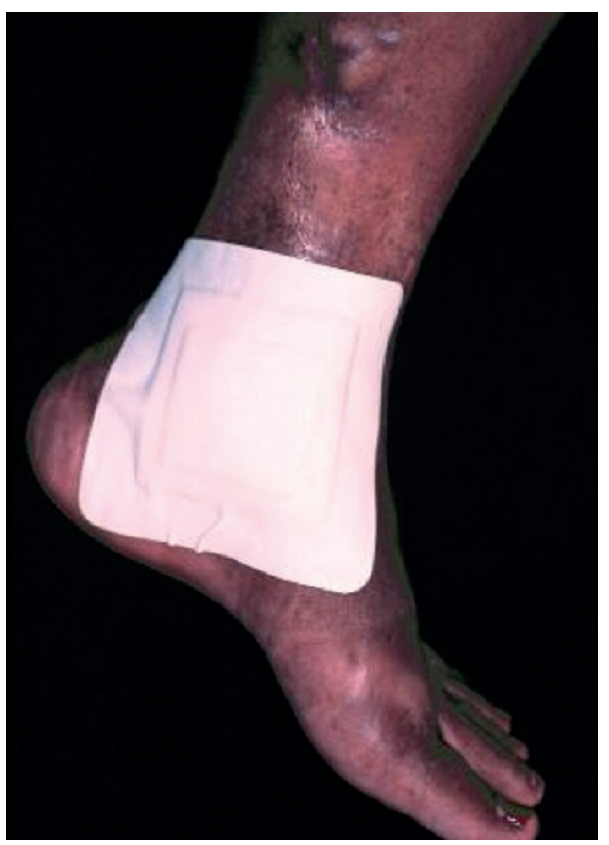

Figure 2: Foam or hydropolymer dressing

Source: Dermatology Department of Botucatu Medical School

\section{Calcium alginate}

Composition: linear polysaccharides prepared from calcium alginate salts, the major components of brown seaweed (Figure 3)

Action: forms a hydrophilic gel through the ion-exchange mechanism. Some alginate dressings contain silver for antibacterial action, and calcium for blood coagulation

Indication: Wounds with moderate to high amount of exudate. Post-operative wounds or post-bleeding debridement

Dressing change: within 7 days, according to saturation

Advantages: changes in dressings are relatively painless, and the newly formed granulation tissue is not harmed. Alginates interact with the wound by donating calcium ions in exchange for the sodium ions present in the wound exudate, facilitating blood clotting, thus aiding hemostasis. Alginate dressing also activates macrophages, leading them to produce the cytokines involved in systemic inflammation, which may encourage healing

Limitations: some patients report a burning sensation. In some cases, exudate may be retained in the wound bed, especially under compression, which may lead to maceration and infection ${ }^{25,35}$

Cost: measuring $10 \times 10 \mathrm{~cm} \mathrm{R} \$ 40 /$ unit

Trading names: Curate $^{\circledR}$ calcium alginate and sodium, Kaltostat ${ }^{\circledast}$, Algicare ${ }^{\circledR}$, Biatain alginate ${ }^{\circledR}$, Suprasorb $^{\circledast}$ A

\section{Alginate with collagen}

Composition: contains $90 \%$ bovine collagen and 10\% calcium alginate (Figure 4)

Action: When these two elements are combined, gel forms at the interface of the dressing and wound bed, promoting a moist environment and controlled dispersion of collagen. Humidity is chemotactic for polymorphonuclear cells, macrophages and fibroblasts, while collagen provides support for cell attachment and growth. The presence of calcium alginate provides hemostatic effect ${ }^{37}$

Indication: wounds with low to moderate level of exudate; due to the hemostatic effect, this dressing can be used on bleeding wounds

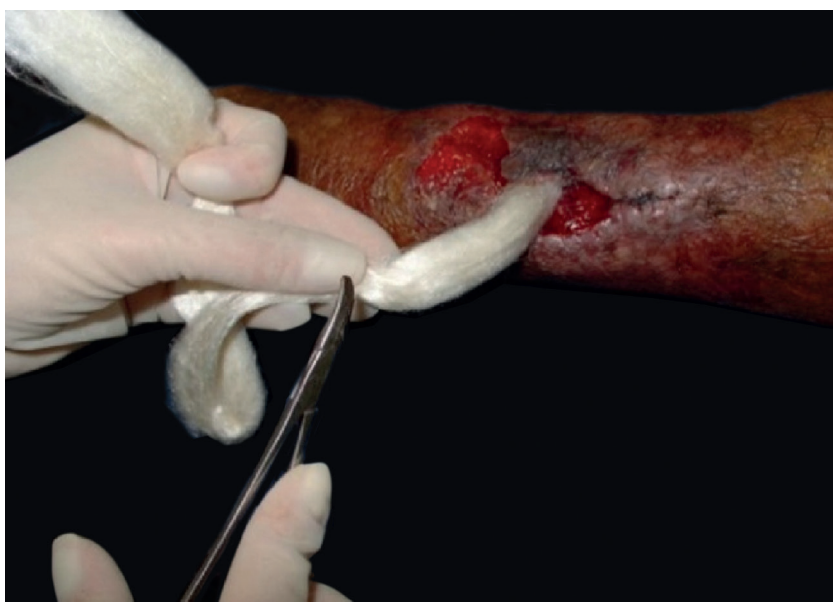

FIGURE 3: Calcium alginate dressing in the form of a tape after surgical dehiscence

Source: Dermatology Department of Botucatu Medical School 


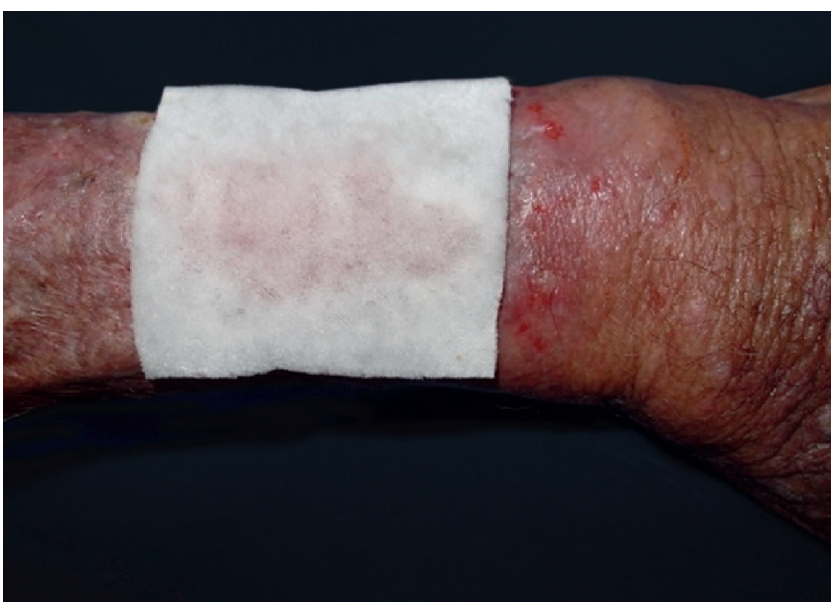

FIGURE 4: Alginate with collagen dressing

Source: Dermatology Department of Botucatu Medical School

Dressing change: up to 3 days

Advantages: the collagen tends to be absorbed by the wound bed, serving as substrate for the formation of the basal layer of the skin

Limitations: it is not indicated for wounds that are very exudative, contain devitalized tissue, and have signs of infection

Cost: measuring 10.2 X 11.1cm R \$ 140 / unit

Trading names: Fibracol ${ }^{\circledR}$

\section{Activated carbon with silver}

Composition: layer of activated carbon impregnated with silver, inserted in a non-woven sachet. Activated charcoal is typically made from natural sources such as rice, coconut, or wood these highly porous materials provide a large area for adsorption of various types of gases, bacteria and liquids. It is obtained by the combustion or decomposition of carbonaceous materials (Figure 5) ${ }^{38}$

Action: activated charcoal layer adsorbs the bacteria, removing them from the lesion bed. Silver has bactericidal activity

Indication: wounds with medium to high amount of exudate with critical colonization or infected

Dressing change: up to seven days, depending on saturation

Advantages: exudate, bacterial and odor control

Limitations: it can adhere to the wound bed, causing painful dressing changes

Cost: measuring $10 \times 10 \mathrm{~cm} \mathrm{R} \$ 45 /$ unit

Trading names: Curatec ${ }^{\circledR}$ activated carbon with silver, Act carbon $\mathrm{Ag}^{\oplus}$, Actsorb Plus ${ }^{\circledast}$, Carboflex $^{\circledR}$

\section{Hydrofiber with and without silver}

Composition: carboxymethylcellulose sodium

Action: These fibers make dressing soft, can gel upon contact with the fluid, and have high fluid retention and absorption. The gel promotes healing of wet wounds; however, it also allows vertical absorption and retention of exudates from the wound, ensuring that peri-ulcer skin is not macerated. The fibers also seques-

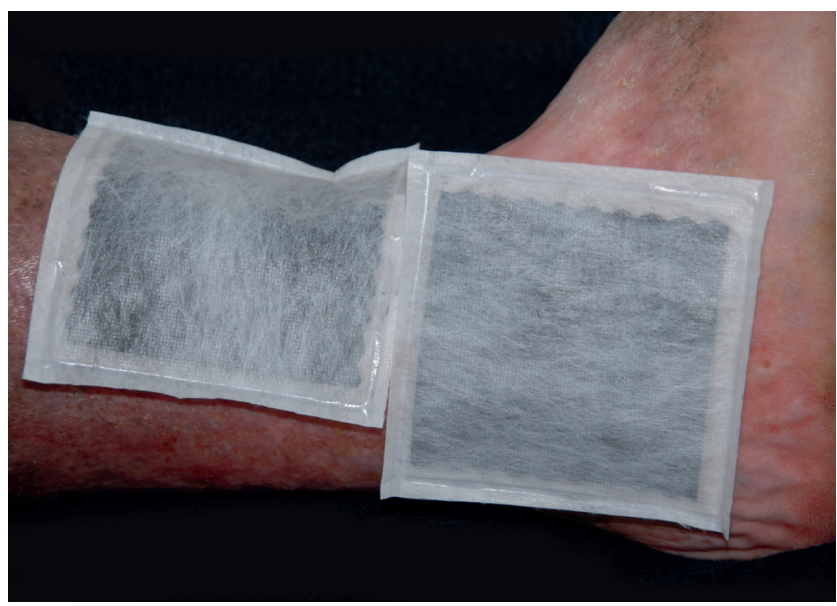

FIGURE 5: Activated carbon with silver dressing on venous ulcers with critical colonization

Source: Dermatology Department of Botucatu Medical School

ter and bind the bacteria inside their structure, thus reducing the possibility of infection. There is a new version of the product on the market, containing antimicrobial (ionic silver) and anti-biofilm (excipients destabilizers of biofilm) agents that favor the breakage, and prevent the reformation, of the biofilm ${ }^{39}$

Indication: wounds with medium to high amount of exudate. Hydrofiber dressings that contain silver are indicated for critically colonized/infected wounds

Dressing change: up to seven days, depending on saturation

Advantages: exudate and biofilm control

Limitations: carboxymethylcellulose filaments are physiologically inert, acting primarily for retention and absorption of exudate ${ }^{25}$

Cost: measuring $10 \times 10 \mathrm{~cm} \mathrm{R} \$ 50 /$ unit

Trading names: Aquace ${ }^{\circledR}$ and Aquacel $\mathrm{Ag}^{\circledR}$

\section{Nanocrystalline silver-impregnated dressing}

Composition: a layer of high-density polyethylene mesh coated with silver nanocrystalline and a layer of rayon and absorbent polyester (Figure 6)

Action: Sustained release ensures that silver remains effective for up to 3 days, protecting wounds against bacterial contamination, in addition to the bactericidal action ${ }^{23}$

Indication: indicated as an antimicrobial barrier on wounds with partial and total tissue loss, such as second-degree burns

Dressing change: up to seven days, depending on the saturation

Advantages: sustained release of silver in wound bed

Limitations: contraindicated for patients with silver sensitivity. Do not use in patients who will undergo magnetic resonance

Cost: measuring $10 \times 12.5 \mathrm{~cm} \mathrm{R} \$ 300 /$ unit

Trading names: Acticoat ${ }^{\circledR}$

\section{Cellulose biomembrane dressing}

Composition: bioproduct in which bacterium uses sucrose 


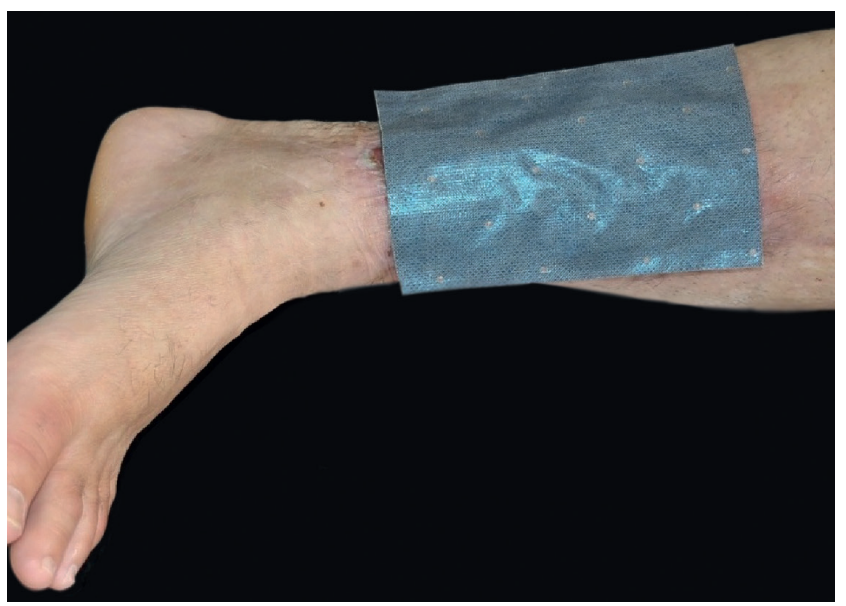

FIGURE 6: Nanocrystalline silver-impregnated dressing

Source: Dermatology Department of Botucatu Medical School

to produce a cellulose-like material-i.e., one property of the bacterium is the production of a biopolysaccharide-resulting in thin films or other compositions, producing a highly hydrated film of randomly assembled fibers in the form of tape less than $100 \mathrm{~nm}$ wide. The various means of producing the membrane include use of the rubber tree Hevea brasiliensis or sugar cane (Figure 7) ${ }^{40-42}$

Action: the matrices are developed to support the cells, promoting cell differentiation and proliferation, favoring the formation of new tissue ${ }^{43}$

Indication: as a temporary replacement skin in the treatment of burns and lesions that are difficult to heal

Dressing change: up to 3 days

Advantages: easy application

Limitations: clinical trials are needed to demonstrate its efficacy. Not indicated for hemorrhages or for tunnel or cavitary lesions

Cost: measuring $10 \times 10 \mathrm{~cm} \mathrm{R} \$ 30 /$ unit

Top trade names: Membracel $^{\circledast}, \mathrm{Nexfill}^{\circledast}, \mathrm{Nanoskin}^{\circledR}$

\section{Negative pressure therapy}

Composition: the principle of negative pressure therapy is to extend the effect of wound suction drainage, using reticulated foam that fits the contour of the wound. To prevent air leakage, wound and foam are hermetically sealed with a polyurethane film that is permeable to water vapor, transparent and anti-bacterial. A suction cup is applied over a small orifice and connected via tube to a vacuum source (Figure 8$)^{35,44}$

Action: The following mechanisms of action may be considered the main effects in healing and thus potential clinical benefits of negative pressure therapy:

Reduction of wound area secondary to negative pressure, which acts on the foam and joining edges of the wound (wound retraction)

Promoting the formation of granulation tissue through the optimal formation of a moist environment, induced by cellular micro-deformations

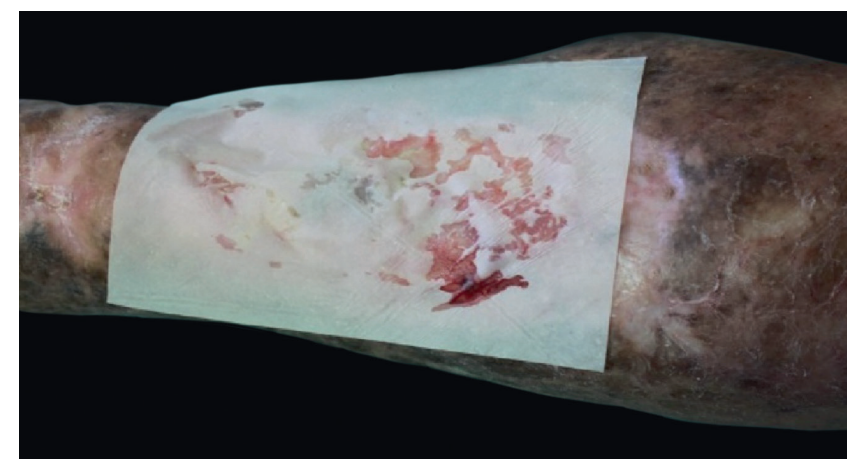

FIGURE 7: Cellulose biomembrane dressing

Source: authors

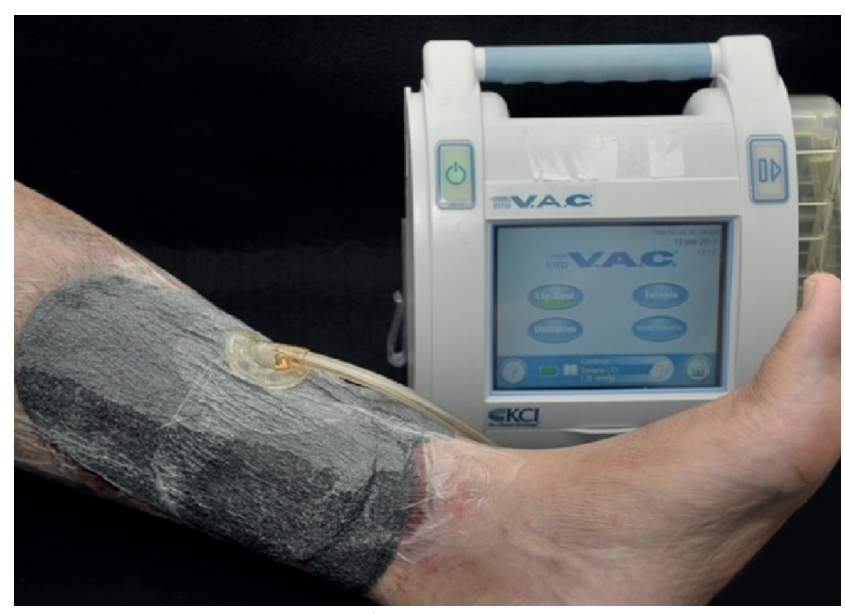

FIGURE 8: Negative pressure therapy

Source: Dermatology Department of Botucatu Medical School

Continuous, effective wound cleaning (mechanical debridement by removal of small non-viable tissues through suction) after adequate surgical debridement of the wound

Continuous removal of exudate and consequent reduction of the need to change the dressing in a closed system

Reduction of interstitial edema pressure with consequent increase of microcirculation (better nutrient perfusion) ${ }^{44}$

One of the latest trends in negative pressure therapy is an added instillation that allows the introduction of a solution into the wound bed during therapy. The fluid essentially washes and irrigates the wound while permitting the intermittent removal of fluid and negative pressure. Various system functions can be adjusted, including the type and amount of solution, amount and timing of negative pressure, and duration of the solution. The ability to remove infection and non-viable materials has also been suggested. This version of negative pressure therapy with instillation is not available yet on the Brazilian market ${ }^{45}$

Indication: complex wounds that need fast bed preparation for healing or graft skin, such as after necrotizing fasciitis, surgical dehiscence, and diabetic foot. It is being used as an adjunct therapy with skin grafting and bioengineered alternative tissues to enhance graft adhesion and as a covering on high risk incisions ${ }^{45}$ 
CHART 1: Indication of main products for wound care, according to the assessment based on the acronym TIME

\begin{tabular}{|c|c|c|c|c|}
\hline $\begin{array}{l}\text { Tissue evaluation } \\
\text { (T of TIME) }\end{array}$ & $\begin{array}{l}\text { Good granulation tissue } \\
\text { (bright red tissue) }\end{array}$ & $\begin{array}{l}\text { Fibrinoid tissue or humid } \\
\text { necrosis (yellow) }\end{array}$ & $\begin{array}{l}\text { Dry necrosis (black } \\
\text { tissue) }\end{array}$ & \\
\hline Objective & Maintenance & Cleaning and debridement & Debridement & \\
\hline \multirow[t]{7}{*}{ Treatment } & Non-adherent gauze & Polyhexanide + betaine & $\begin{array}{l}\text { Hydrogel with } \\
\text { alginate }\end{array}$ & \\
\hline & Cellulose membrane & Hydrogel with alginate & Papain & \\
\hline & Hydrogel & Papain & Collagenase & \\
\hline & Hydrocolloid & Collagenase & Fibrinolysin & \\
\hline & Polyurethane film & Fibrinolysin & & \\
\hline & Foam & & & \\
\hline & Alginate with collagen & & & \\
\hline $\begin{array}{l}\text { Evaluation of in- } \\
\text { fection/ Inflamma- } \\
\text { tion (I do TIME) }\end{array}$ & YES & NO & & \\
\hline Objective & Cleaning and treatment & Maintenance & & \\
\hline \multirow[t]{3}{*}{ Treatment } & $\begin{array}{l}\text { Antiseptic solutions: } \\
\text { Polyhexanide + betaine; } \\
\text { Cadexomer iodine; }\end{array}$ & $\begin{array}{l}\text { According to tissue evaluation } \\
\text { and degree of exudation }\end{array}$ & & \\
\hline & Calcium Alginate & & & \\
\hline & $\begin{array}{l}\text { Silver-impregnated dress- } \\
\text { ing (Activated charcoal, } \\
\text { hydrofiber and foam) }\end{array}$ & & & \\
\hline $\begin{array}{l}\text { Moisture Evalua- } \\
\text { tion (M of TIME) }\end{array}$ & DRY WOUND & MILD EXUDATION & $\begin{array}{l}\text { MODERATE } \\
\text { EXUDATION }\end{array}$ & HEAVY EXUDATION \\
\hline Objective & Consider hydration & Maintenance & Control & Control \\
\hline \multirow[t]{4}{*}{ Treatment } & Hydrogel & According to tissue evaluation & Calcium alginate & $\begin{array}{l}\text { Negative pressure } \\
\text { Therapy }\end{array}$ \\
\hline & Hydrocolloid & & Foam & $\begin{array}{l}\text { Calcium alginate, } \\
\text { Activated charcoal }\end{array}$ \\
\hline & & & Activated charcoal & Hydrofiber \\
\hline & & & Hydrofiber & \\
\hline $\begin{array}{l}\text { Edge Evaluation } \\
\text { (E of TIME) }\end{array}$ & ADHERED & UNDERMINED & MACERATED & \\
\hline Objective & Maintenance & Fill & Exudate control & \\
\hline \multirow[t]{3}{*}{ Treatment } & $\begin{array}{l}\text { According to tissue } \\
\text { evaluation and degree of } \\
\text { exudation }\end{array}$ & Calcium alginate & Calcium alginate & \\
\hline & & Alginate with collagen & Foam & \\
\hline & & Activated charcoal, Hydrofiber & $\begin{array}{l}\text { Activated charcoal } \\
\text { Hydrofiber }\end{array}$ & \\
\hline
\end{tabular}

Source: authors

Dressing change: up to 5 days

Advantages: high rates of tissue granulation and vascularization in the wound bed, control of bacterial growth and contamination, reduced number of dressing changes, reduced edema, as well as possible economic advantages ${ }^{45}$

Limitations: the wounds should be completely debrided from all necrotic tissues prior to the initiation of therapy. In some patients, dressing changes can be painful or cause trauma to the wound bed, due to the growth of the new granulation tissue through the foam; the use of denser sheets or more frequent changes may help relieve this problem ${ }^{35}$

Cost: per dressing kit $\mathrm{R} \$ 1200$ to $\mathrm{R} \$ 1800$, varying by size

Top trade names: Renasys ${ }^{\circledR}$, Sistema de Terapia V.A.C. ${ }^{\circledR}$, Simex $^{\circledR}$ 
CHART 2: Indication of main products for wound care, according to the type of injury

\begin{tabular}{|c|c|}
\hline $\begin{array}{l}\text { Wound type } \\
\text { Acute }\end{array}$ & Dressing \\
\hline Skin tears & Non-adherent gauze \\
\hline Epidermolysis bullosa & $\begin{array}{l}\text { Polyurethane film non-adherent } \\
\text { gauze and foams or hydropolymers }\end{array}$ \\
\hline Surface burns & Hydrofiber with or without silver \\
\hline Traumatic injuries & $\begin{array}{l}\text { Foam or hydropolymers (with } \\
\text { silicone) }\end{array}$ \\
\hline Deep burns & $\begin{array}{l}\text { Depends on tissue type evaluation } \\
\text { - silver dressing is indicated for } \\
\text { infection control }\end{array}$ \\
\hline Surgical dehiscence & $\begin{array}{l}\text { Depends on TIME evaluation - } \\
\text { calcium alginate dressing is indicated } \\
\text { for hemostatic control; in some cases, } \\
\text { negative pressure therapy }\end{array}$ \\
\hline \multicolumn{2}{|l|}{ Chronic } \\
\hline \multicolumn{2}{|l|}{ Pressure injury* } \\
\hline Stage I & Foam or hydropolymers \\
\hline Stage II, III and IV & Depends on TIME evaluation \\
\hline Vasculogenic ulcers** & Depends on TIME evaluation \\
\hline Oncologic wound & $\begin{array}{l}\text { Depends on TIME evaluation and } \\
\text { care objective }\end{array}$ \\
\hline
\end{tabular}

*Includes positioning for pressure relief

**Includes treatment for cause of ulcer (e.g., compression therapy for venous ulcers) Source: authors

\section{CONCLUSIONS}

Wound treatment is a dynamic process that requires knowledge and preparation by professionals to deal with the difficulties of healing, particularly for chronic wounds. Given the variety of treatments, a combination of modalities is suggested, based on the various factors involved in healing.

Chart 1 summarizes the main products for wound treatment according to the evaluation based on the acronym TIME, and chart 2 summarizes the indications of the main products for wound care, according to the type of injury. $\square$

\section{REFERENCES}

1. International Wound Infection Institute (IWII). Wound infection in clinical practice: principles of best practice. London: Wounds International; 2016. p. 32.

2. Harries RL, Bosanquet DC, Harding KG. Wound bed preparation : TIME for an update. Int Wound J. 2016;13(Suppl 3):8-14.

3. Leaper DJ, Schultz G, Carville K, Fletcher J, Swanson T, Drake R. Extending the TIME concept: what have we learned in the past 10 years $\left.{ }^{*}{ }^{\star}\right)$. Int Wound J. 2012;9(Suppl 2):1-19.

4. World Union of Wound Healing Societies (WUWHS). Florence Congress, Position Document. Management of Biofilm. Florence: Wounds International; 2016.

5. Rüttermann M, Maier-Hasselmann A, Nink-Grebe B, Burckhardt M. Local treatment of chronic wounds: in patients with peripheral vascular disease, chronic venous insufficiency, and diabetes. Dtsch Arztebl Int. 2013;110:25-31.

6. Borges EL, Caliri MHL, Haas VJ. Systematic review of topic treatment for venous ulcers. Rev Lat Am Enfermagem. 2007;15:1163-70.

7. Moriya T, Módena JLP. Assepsia e antissepsia: técnicas de esterilização. Medicina (Ribeirão Preto). 2008;41:265-73.

8. Eberlein T, Assadian 0. Clinical use of polihexanide on acute and chronic wounds for antisepsis and decontamination.Skin Pharmacol Physiol. 2010;23:45-51.

9. Wound, Ostomy and Continence Nurses Society (WOCN) Wound Committee; Association for Professionals in Infection Control and Epidemiology, Inc. (APIC) 2000 Guidelines Committee. Clean vs. sterile dressing techniques for management of chronic wounds: a fact sheet. J Wound Ostomy Continence Nurs. 2012;39(Suppl):S30-4.

10. Ferreira AM, Andrade D. Integrative review of the clean and sterile technique: agreement and disagreement in the execution of dressing. Acta Paul Enferm. 2008;21:117-21.

11. Fernandez R, Griffiths R. Water for wound cleansing. Cochrane Database Syst Rev. 2012:CD003861

12. Lipsky BA, Hoey C. Topical antimicrobial therapy for treating chronic wounds.Clin Infect Dis. 2009;49:1541-9.
13. Vermeulen H, Westerbos SJ, Ubbink DT. Benefit and harm of iodine in wound care: a systematic review. J Hosp Infect. 2010;76:191-9.

14. Oliveira AS, Santos VLCG. Topical iodophor use in chronic wounds: a literature review. Rev Lat Am Enfermagem. 2007:15:671-6.

15. Kaehn K. Polihexanide: a safe and highly effective biocide. Skin Pharmacol Physiol. 2010;(Suppl):S7-16

16. Gethin G, Cowman S, Kolbach DN. Debridement for venous leg ulcers. Cochrane Database Syst Rev. 2015;9:CD008599.

17. Klein S, Schreml S, Dolderer J, Gehmert S, Niederbichler A, Landthaler M, et al. Evidence-based topical management of chronic wounds according to the T.I.M.E. principle. J Dtsch Dermatol Ges. 2013;11:819-29.

18. Atkin L, Rippon M. Autolysis: mechanisms of action in the removal of devitalised tissue. Br J Nurs. 2016;25(Suppl):S40-S47.

19. Eberlein T, Assadian 0 . Clinical use of polihexanide on acute and chronic wounds for antisepsis and decontamination. Skin Pharmacol Physiol. 2010;23(Suppl):S45-51.

20. Motley TA, Gilligan AM, Lange DL, Waycaster CR, Dickerson JE Jr. Costeffectiveness of clostridial collagenase ointment on wound closure in patients with diabetic foot ulcers: economic analysis of results from a multicenter, randomized, open-label trial. J Foot Ankle Res. 2015;8:7.

21. Omar A, Wright JB, Schultz G, Burrell R, Nadworny P. Microbial Biofilms and Chronic Wounds. Microorganisms. 2017:5:1-12.

22. O'Meara S, Al-Kurdi D, Ologun Y, Ovington LG, Martyn-St James M, Richardson R. Antibiotics and antiseptics for venous leg ulcers. Cochrane Database Syst Rev. 2014:CD003557.

23. Carter MJ, Tingley-Kelley K, Warriner RA 3rd. Silver treatments and silverimpregnated dressings for the healing of leg wounds and ulcers: a systematic review and meta-analysis. J Am Acad Dermatol. 2010 0c;63:668-79.

24. McVeigh $\mathrm{H}$. Topical silver for preventing wound infection. Int J Evid Based Healthc 2011:9:454-5. 
25. Sweeney IR, Miraftab M, Collyer G. A critical review of modern and emerging absorbent dressings used to treat exuding wounds. Int Wound J. 2012;9:601-12

26. Pereira AL, Bachion MM. Wound treatment: scientific production analysis published in the Revista Brasileira de Enfermagem from 1970-2003. Rev Bras Enferm. 2005:58:208-13.

27. Ferreira AM, Souza BMV, Rigotti MA, Loureiro MRD. The use of fatty acids in wound care: an integrative review of the Brazilian literature. Rev Esc Enferm USP 2012; $46: 745-53$

28. McCallon SK, Weir D, Lantis JC 2nd. Optimizing Wound Bed Preparation With Collagenase Enzymatic Debridement. J Am Coll Clin Wound Spec. 2015;6:14-23.

29. Tallis A, Motley TA, Wunderlich RP, Dickerson JE Jr, Waycaster C, Slade HB Collagenase Diabetic Foot Ulcer Study Group. Clinical and Economic Assessment of Diabetic Foot Ulcer Debridement with Collagenase : Results of a Randomized Controlled Study. Clin Ther. 2013;35:1805-20. Clin Ther. 2013;35:1805-20.

30. Falabella AF, Carson P, Eaglstein WH, Falanga V. The safety and efficacy of a proteolytic ointment in the treatment of chronic ulcers of the lower extremity. J Am Acad Dermatol. 1998;39:737-40.

31. Aguiar Jr AC, Isaac C, Nicolosi JT, Medeiros MMM, Paggiaro A0, Gemperli R. Analysis of the clinical care of patients with chronic ulcers of the lower limbs. Rev Bras Cir Plást. 2015;30:258-63.

32. Franco D, Gonçalves LF. Feridas cutâneas: a escolha do curativo adequado. Rev Col Bras Cir. 2008;35:203-6.

33. Malone M, Johani K, Jensen SO, Gosbell IB, Dickson HG, McLennan S, et al. Effect of cadexomer iodine on the microbial load and diversity of chronic non-healing diabetic foot ulcers complicated by biofilm in vivo. J Antimicrob Chemother 2017;72:2093-101

34. Saco M, Howe N, Nathoo R, Cherpelis B. Topical antibiotic prophylaxis for prevention of surgical wound infections from dermatologic procedures: a systematic review and meta-analysis. J Dermatolog Treat. 2015;26:151-8.
35. Fonder MA, Lazarus GS, Cowan DA, Aronson-Cook B, Kohli AR, Mamelak AJ. Treating the chronic wound: A practical approach to the care of nonhealing wounds and wound care dressings. J Am Acad Dermatol. 2008;58:185-206.

36. Tayyib N, Coyer F. Effectiveness of Pressure Ulcer Prevention Strategies for Adult Patients in Intensive Care Units : A Systematic Review. Worldviews Evid Based Nurs. 2016;13:432-44.

37. Carvalho VF, Paggiaro A0, Gringlas J, Isaac C, Gomes DS, Ferreira MC. Ensaio clínico para tratamento da área doadora de enxerto de pele de espessura parcial: aplicação do curativo de colágeno associado ao filme de poliuretano. Rev Bras Queimaduras. 2009;8:60-4.

38. Akhmetova A, Saliev T, Allan IU, Illsley MJ, Nurgozhin T, Mikhalovsky S. A Comprehensive Review of Topical Odor-Controlling Treatment Options for Chronic Wounds. J Wound Ostomy Continence Nurs. 2016;43:598-609.

39. Metcalf DG, Parsons D, Bowler PG. Clinical safety and effectiveness evaluation of a new antimicrobial wound dressing designed to manage exudate, infection and biofilm. Int Wound J. 2017:14:203-13.

40. Frade MA, Coutinho Netto J, Gomes FG, Mazzucato EL, Andrade TA, Foss NT. Natural-biomembrane dressing and hypersensitivity. An Bras Dermatol. 2011;86:885-91

41. Basmaji P. Nanoskin ${ }^{\circledR}$ for medical applications. NSTI-Nanotech. 2011;3:193-6.

42. Mualla S Al, Farahat R, Basmaji P, Olyveira GM De, Maria L, Costa M, et al. Study of Nanoskin ECM-Bacterial Cellulose Wound Healing / United Arab Emirates. J Biomater Nanobiotechnol. 2016;7:109-17.

43. Lin WC, Lien CC, Yeh HJ, Yu CM, Hsu SH.. Bacterial cellulose and bacterial cellulose-chitosan membranes for wound dressing applications. Carbohydr Polym. 2013;94:603-11.

44. Back DA, Scheuermann-Poley C, Willy C. Recommendations on negative pressure wound therapy with instillation and antimicrobial solutions - when , where and how to use : what does the evidence show? Int Wound J. 2013;10(Suppl 1):S32-42

45. Garwood CS, Steinberg JS. What's new in wound treatment: a critical appraisal. Diabetes Metab Res Rev. 2016;32(Suppl 1):268-74.

How to cite this article: Colenci R, Abbade LPF. Fundamental aspects of the local approach to cutaneous ulcers. An Bras Dermatol. 2018;93(6):859-70. 